\title{
Polycystic ovary syndrome in adolescents with obesity
}

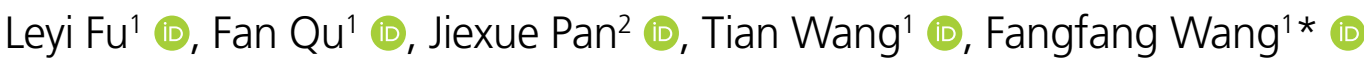

\section{SUMMARY}

INTRODUCTION: Polycystic ovary syndrome (PCOS) is one of the most common endocrine disorders in women of reproductive age with the prevalence from $5 \%$ to $15 \%$, and the prevalence of PCOS in adolescents with obesity seems even higher. The weight status is significantly associated with the quality of life in adolescents with PCOS.

OBJECTIVE: This review aims to summarize the latest findings of pathogenesis, diagnosis, comorbidity, and management in PCOS adolescents with obesity.

METHODS: This is a narrative review of articles published in PubMed from June 2013 to June 2020 Data were searched using the key words of "polycystic ovary syndrome" AND "adolescent" AND "obesity."

RESULTS: Pubertal obesity, particularly central obesity, could have a negative impact on the pathophysiology of PCOS. In adolescents with obesity, a review of medical history and a long-term follow-up for PCOS symptoms are essential to avoid misdiagnosis. There is a link between obesity and comorbidities of PCOS in adolescents. Holistic treatment and concern for related comorbidities should ideally begin as early as possible in obese adolescents once the diagnosis of PCOS is confirmed.

CONCLUSION: Adolescents with PCOS and obesity need more attention from physicians and researchers, and the effective interventions in the early stage are critical to improve their life quality.

KEYWORDS: Polycystic ovary syndrome. Adolescent. Obesity.

\section{INTRODUCTION}

Polycystic ovary syndrome (PCOS) is one of the most common endocrine disorders in women of reproductive age with the prevalence from $5 \%$ to $15 \%$, and the primary cause of anovulatory female infertility. ${ }^{1-2}$ It was reported that many manifestations and biomarkers of PCOS changed with the advancing age, involving androgen concentrations, fat distribution, and menstrual irregularity. ${ }^{3}$
Obesity, especially visceral obesity, is common among adolescences and adults with PCOS. ${ }^{4} \mathrm{~A}$ recent study indicating that the prevalence of PCOS among overweight or obese pubertal patients seemed to be higher than in adult patients, ${ }^{5}$ and its prevalence seemed to be associated with the state of obesity in adolescent girls. ${ }^{6}$ In addition, it was shown that weight status was closely associated with the relationship between PCOS and health-related quality of life in those girls with PCOS, ${ }^{7}$ and the

'Women's Hospital, School of Medicine, Zhejiang University, Hangzhou, China.

${ }^{2}$ Obstetrics \& Gynecology Hospital, Institute of Reproduction and Development, Fudan University, Shanghai, China.

*Corresponding author: Drwangfangfang@zju.edu.cn

Conflicts of interest: the authors declare there are no conflicts of interest. Funding: National Natural Science Foundation of China under Grant 81873837 for FW and 81801411 for JP.

Received on January 06, 2021. Accepted on January 09, 2021. 
risk factors related to metabolic syndrome were also found in obese adolescents with PCOS. ${ }^{8-9}$

Treatments of PCOS include not only improvement of menstrual cycles and hirsutism but also reducing risk factors of metabolic syndrome and cardiovascular events, such as insulin resistance, dyslipidemia, and obesity. ${ }^{10}$ Considering the impact of obesity on adolescents, the early-stage interventions should play an important role in this population. Therefore, the aim of this article was to conduct a narrative review of PCOS in obese adolescents, including the pathogenesis, diagnosis, comorbidity, and management. This review might also contribute to improving the quality of life in obese girls with PCOS.

\section{METHODS}

In this narrative review, we searched the PubMed database using the following key words: "polycystic ovary syndrome" AND "obesity" AND "adolescent." The inclusion criteria for selection were as follows: articles in the English language and articles published during the period of 7 years (June 2013-June 2020), with studies related to obese adolescents with PCOS. We excluded studies that did not specify which populations were probably involved, either adults or nonobese people.

\section{RESULTS}

First, we found 455 studies related to this subject, of which 30 were included for this review after further exclusion. Then we summarized the results and divided them into four aspects, including pathogenesis, diagnosis, comorbidity, and management in PCOS adolescent with obesity.

\section{Pathogenesis}

Adolescent PCOS was the outcome of a mismatch between energy saving and obesogenic environment. ${ }^{6}$ The hypothesis of adipose tissue expandability speculated that hyperinsulinemic androgen excess in PCOS was usually caused by depletion of the capacity to expand subcutaneous adipose tissue in a metabolically safe way. If prenatal weight gain was less than postnatal weight gain, more fat would be stored in central tissues than in subcutaneous adipose, which induced central obesity. ${ }^{11}$ However, young girls might increase the speed of their growth and/or maturation to avoid such central obesity. ${ }^{12}$ At adolescence and adulthood, this homeostatic mechanism could be out of balance and PCOS might ensue. ${ }^{13}$ It was reported that high body mass index (BMI) during childhood was associated with menstrual irregularity, and weight gain during adolescence to adulthood was also related to PCOS. ${ }^{14-15}$ In addition, omentin-1, an adipokine secreted essentially by visceral adipose tissue, was negatively correlated with free testosterone level in obese girls with PCOS as compared with obese girls without PCOS, suggesting that virilization of adipose tissue might have a role in the pathogenesis of PCOS via alternating adipokine profile. ${ }^{16}$ In addition, S100A4, a marker of subcutaneous adipose tissue dysfunction, might become a circulating marker of hepato-visceral fat excess in adolescents with PCOS. ${ }^{17}$

Pubertal obesity was one of the adverse factors underlying the pathophysiology of PCOS in adolescents. First, considering the role of mitochondrial dysfunction and systemic inflammation played in the pathogenesis of PCOS in adult patients, it was investigated that manifestations of oxidative stress and systemic inflammation also performed in overweight adolescents with PCOS, but less obvious in PCOS adolescents with normal weight due to the homeostasis control system and adaptive compensative mechanism of antioxidant defense in adolescence. ${ }^{18}$ In addition, obesity could exacerbate the insulin-resistant (IR) and hyperinsulinemia to aggravate hyperandrogenism indirectly, ${ }^{19}$ and peripubertal obesity was a potential factor of hyperandrogenism, which was especially prominent in early puberty. ${ }^{20}$ It was found that obese adolescents with PCOS had significantly lower sex hormone-binding globulin (SHBG) and significantly higher free testosterone levels as compared with normal-weight girls with PCOS. ${ }^{21}$ Furthermore, the free testosterone levels were significantly higher in obese adolescents with PCOS than those without PCOS. ${ }^{21}$

In summary, pubertal obesity, including central obesity, is associated with PCOS, which reminds physicians to perceive the appearance of PCOS. Early interventions need to put on PCOS adolescents with increased BMI to restrict weight as obesity could have a negatively multifactor impact on the pathophysiology of PCOS in the pubertal time.

\section{Diagnosis}

The diagnosis of PCOS in adolescents was challenging, because of the overlap of the normal puberty with manifestations of PCOS, such as menstrual irregularity, acne, and hirsutism, and now mainly determined by the coexisting of menstrual irregularity and hyperandrogenism according to different published guidelines. ${ }^{22}$

Obesity in puberty might be an important marker for the diagnosis of PCOS in the early stage. A prospective study indicated that early adiposity rebound, the second rise in BMI following a nadir occurring before 5 years old, was correlative with the diagnosis of PCOS. It was crucial for adolescents with adiposity rebound and continuous obesity to screen for PCOS manifestations, such as persistently menstrual irregularities and hirsutism. ${ }^{23}$ In addition, adolescents "at risk" of PCOS are those who only have a single condition of PCOS 
diagnostic criteria, that is, irregular menstrual cycles or clinical hyperandrogenism. These adolescents needed reassessment in menstrual cycle irregularity at 3-year post-menarche and polycystic ovarian morphology at 8 years post menarche, which was particularly important for those with persisting PCOS features and significant weight gain. ${ }^{24}$ In addition, the cutoff of hirsutism score with Ferriman-Gallwey index was associated with ethnic background, and the diagnosis of hirsutism might create psychological pressure for women, and even more for adolescents. Thus, accurate cutoff of diagnostic criteria of hyperandrogenism needs more studies to verify in order to avoid overdiagnosis. ${ }^{25}$

The serum level of anti-Müllerian hormone (AMH) is correlated to the antral follicular count or the excessive number of follicles per ovary. ${ }^{26}$ The serum AMH levels in adolescents and adults with PCOS were mostly higher than in those without PCOS, but they were not recommended for PCOS diagnosis due to insufficient studies and inaccurate standard for different populations. ${ }^{24}$ Considering the difficulties of performing vaginal ultrasound in obese adolescent girls and distinguishing PCOS-related hyperandrogenic manifestations from obesity-related alterations, a study reported that the $\mathrm{AMH}$ of 6.26 $\mathrm{ng} / \mathrm{mL}$ seemed to be an optimal cutoff value in obese girls for predicting PCOS; addition of SHBG and total testosterone to $\mathrm{AMH}$ increased the predictive power to $93.4 \%$ for diagnosing PCOS. ${ }^{27}$

In conclusion, a review of medical history and a long-term follow-up of symptoms related to PCOS were important for adolescents with obesity to avoid misdiagnosis. In addition, obese adolescents, especially "at risk" of PCOS, with high serum levels of AMH need more attention to detect the alterations of manifestations associated with PCOS.

\section{Comorbidity}

The presence of obesity seems to be clearly associated with metabolic syndromes and psychological issues in adolescents with PCOS. The prevalence of abnormal glucose metabolism in adolescent patients with PCOS was reported at $17.2 \%$, who were mostly overweight or obese. ${ }^{8}$ In obese girls with PCOS, more markers of cardiovascular disease (CVD) risk were found as compared with those without PCOS. ${ }^{9}$ Furthermore, it was found that nonalcoholic fatty liver was connected with increasing abdominal adiposity in adolescents with PCOS. ${ }^{28}$ The emotional depress partly was also connected with some certain symptoms of PCOS such as obesity and hirsutism in adolescents with PCOS. ${ }^{29}$ The depression scores were definitely higher with elevated BMI, which meant potentially important interaction between obesity and depression in adolescents with PCOS. ${ }^{30}$
Increasing clinical and laboratory data emerge as early evidence of metabolic disorders in obese adolescents with PCOS. It was reported that elevated fasting and postprandial plasma triglyceride and apolipoprotein (Apo)B-lipoprotein remnants could provide evidence of early subclinical CVD risk in obese girls with PCOS, which were highly associated with impaired insulin metabolism and hyperandrogenaemia. ${ }^{31}$ Moreover, increased pulse wave velocity, vascular cell adhesion molecule-1, and high-sensitivity C-reactive protein might be the earliest subclinical atherosclerosis biomarkers in obese girls with PCOS. ${ }^{32}$ The oral glucose tolerance test (OGTT, using a dose of $1.75 \mathrm{~g} / \mathrm{kg}$ to a maximum of $75 \mathrm{~g}$ ) was a superior diagnostic test to assess abnormal glucose levels in obese girls with PCOS. ${ }^{8}$ In addition, estimate of insulin sensitivity (e-IS), an index without an OGTT derived from waist circumference, fasting triglyceride concentrations, and $\mathrm{HbA1c}$, could predict server IR in girls with PCOS. ${ }^{33}$

In a word, there is also a link between obesity and comorbidities of PCOS in adolescents. Special biomarkers or clinical tests could provide evidences of metabolic disorders in obese adolescents with PCOS, periodical tests for the condition of the liver and emotional counseling are also necessary for those girls.

\section{Management}

The long-term management for reproductive, metabolic, and mental health was suggested once a pubertal girl was diagnosed with PCOS. ${ }^{34}$ It was reported that both lifestyle interventions and pharmacological strategies for weight management were beneficial to obese women with PCOS. ${ }^{35}$ Considering the influence of obesity in PCOS, weight management is important for obese adolescents with PCOS, even for those "at risk" of PCOS.

Lifestyle interventions, with an objective of weight loss, were recommended as a first-line treatment for adolescent PCOS girls with overweight or obesity. ${ }^{36}$ Evidences indicated that successful weight loss in obese PCOS girls was associated with improvement in the menstrual cycle, reduction in androgens, and cardiovascular risk factors. ${ }^{37-39}$ In order to get rid of the side effects of medicine, lifestyle interventions could also be recommended to the obese girls "at risk" of PCOS. Comprehensive lifestyle interventions, including a balanced diet, exercise, behavioral education and psychotherapy, were significantly achieved weight loss. ${ }^{39}$ As we know, women with PCOS had increased appetite and calorie input; therefore, the general management rule of diet was calorie restriction (500-1000 kcal per day) and reduced amount of carbohydrate (not exceeding $200 \mathrm{~g}$ or no more than $30 \%$ of total energy). ${ }^{40}$ It was also shown that low-glycemic load ( $45 \%$ carbohydrate, $35 \%$ fat, $20 \%$ protein) or low-fat ((55\% carbohydrate, $25 \%$ 
fat, $20 \%$ protein)) diet over 6 months were both efficacious for promoting weight loss and reductions in body fat among overweight and obese adolescents with PCOS..$^{41}$ Exercise with at least $60 \mathrm{~min}$ of moderate-to-vigorous intensity physical activity per day, including those that strengthen muscle and bone, at least three times weekly was recommended for adolescents. ${ }^{42}$ However, the optimal exercise dose for promoting weight loss in adolescents with overweight-obesity was still uncertain. ${ }^{43}$ In addition, it was found that poor sleep behaviors were associated with metabolic dysfunction and metabolic symptoms among obese adolescents with PCOS, so sleep health should be included in the assessment of adolescents with PCOS and obesity. ${ }^{44}$

Pharmacological treatments of the combined oral contraceptive pill (COCP) and/or metformin were recommended in adolescents clearly diagnosed with PCOS or in adolescents deemed "at risk" of PCOS for the management of symptoms. In obese adolescents with PCOS, COCP combined with metformin could be considered when COCP and lifestyle changes could not achieve desired targets. ${ }^{24} \mathrm{~A}$ study reported that treatment with metformin or oral contraceptives in obese adolescents with PCOS could lead to reduction in androgen levels, weight loss, and increased insulin and sensitivity. ${ }^{45}$ In addition, lifestyle interventions combined with oral contraceptives and metformin could reduce central adiposity and total testosterone and increase high-density lipoprotein, but could not enhance overall weight reduction. ${ }^{46}$ However, there was no exact recommendation for special types and doses of COCP due to insufficient data in adolescents. ${ }^{24}$ Local therapies like photoepilation were recommended as first-line therapies to treat localized hirsutism in adolescents with PCOS. ${ }^{47}$ Antiandrogens were advised to consider after the use of the COCP alone with cosmetic therapy for at least 6 months, and antiandrogens should only be used when contraceptive measures are guaranteed in those sexually active adolescents. ${ }^{24}$ The use of anti-obesity medications in children and adolescents was not approved..$^{48}$ However, it was found early low-dose combination of spironolactone $50 \mathrm{mg} /$ day, pioglitazone $7.5 \mathrm{mg} /$ day, and metformin $850 \mathrm{mg} /$ day (SPIOMET) treatment for PCOS in adolescent girls normalized posttreatment ovulation rates more than oral contraceptive, with normalizing visceral fat and insulinemia but no significant change on body weight. Thus, the intervention on early reduction of hepato-visceral fat in adolescents with PCOS could be an important strategy. ${ }^{49}$

In summary, weight management is crucial for obese adolescents with PCOS. Holistic treatments should ideally begin at early time once obese adolescents get diagnosed with PCOS in case situations get worse in adults, and weight loss is significantly important in obese adolescents with PCOS or in obese girls "at risk" of PCOS. In addition, treatments of PCOS-related symptoms could be considered for obese girls "at risk" of PCOS.

\section{DISCUSSION}

Polycystic ovary syndrome is one of the most common endocrine disorders in women of reproductive age, and its manifestations could start at pubertal period and change with advancing age. ${ }^{1-3}$ According to our narrative review, pubertal obesity, particularly central obesity, could have an impact on the pathophysiology of PCOS. The diagnosis of PCOS in adolescents with obesity requires a review of medical history and a longterm follow-up of PCOS symptoms to avoid misdiagnosis. There is a link between obesity and comorbidities of PCOS in adolescents. The holistic treatment for obese adolescents with PCOS, involving diet, exercise, emotion, sleep, and concern for comorbidities associated with PCOS should ideally begin at early time once they get diagnosed with PCOS, in case that situation would get worse in adults. This narrative review provides a comprehensive summary of studies about obese adolescents with PCOS in recent years, which might facilitate physicians in clinical practice and arise their awareness to take management in early stage in order to improve long-term health in adults.

However, this review has several limitations. One is that the selection of articles was restricted to one database with one language, which might reduce the number of relevant publications. Another limitation is that the samples involved in most of the included studies were from South America and Europe; this might bias the conclusion about the association between obesity and PCOS toward the above ethnic populations.

\section{CONCLUSIONS}

The pubertal obesity is related to the pathogenesis of PCOS. Obese adolescents with PCOS or "at risk" of PCOS need more attention of physicians to undertake holistic management in time to avoid the deteriorating scenario with advancing age. The exact mechanism underlying the relationship between obesity and PCOS in adolescence is still not fully understood; future work is required to explore its etiology. More studies with a large sample size are needed on the diagnosis criteria, comorbidities supervision, and treatments in obese adolescents with PCOS.

\section{AUTHORS' CONTRIBUTIONS}

LF: Writing - Review and Editing. FQ: Supervision, Writing Review and Editing. JP: Writing - Review and Editing. TW: Writing - Review and Editing. FW: Supervision, Writing Review and Editing. 


\section{REFERENCES}

1. Ehrmann DA. Polycystic ovary syndrome. N Engl J Med. 2005;352(12):1223-36. https://doi.org/10.1056/NEJMra041536

2. Lauritsen MP, Bentzen JG, Pinborg A, Loft A, Forman JL, Thuesen $\mathrm{LL}$, et al. The prevalence of polycystic ovary syndrome in a normal population according to the Rotterdam criteria versus revised criteria including anti-Müllerian hormone. Hum Reprod. 2014;29(4):791-801. https://doi.org/10.1093/humrep/det469

3. Medeiros SF, Yamamoto MMW, Medeiros MAS, Barbosa BB, Soares $J M$, Baracat EC. Changes in clinical and biochemical characteristics of polycystic ovary syndrome with advancing age. Endocr Connect. 2020;9(2):74-89. https://doi.org/10.1530/EC-19-0496

4. Glueck CJ, Goldenberg N. Characteristics of obesity in polycystic ovary syndrome: etiology, treatment, and genetics. Metabolism. 2019;92:108-20. https://doi.org/10.1016/j. metabol.2018.11.002

5. Ybarra M, Franco RR, Cominato L, Sampaio RB, Rocha SMS, Damiani $D$. Polycystic ovary syndrome among obese adolescents. Gynecol Endocrinol. 2018;34(1):45-8. https://doi.org/10.108 0/09513590.2017.1359250

6. Ibáñez $L$, de Zegher F. Polycystic ovary syndrome in adolescent girls. Pediatr Obes. 2020;15(2):e12586. https://doi.org/10.1111/ ijpo.12586

7. Trent M, Austin SB, Rich M, Gordon CM. Overweight status of adolescent girls with polycystic ovary syndrome: body mass index as mediator of quality of life. Ambul Pediatr. 2005;5(2):107-11. https://doi.org/10.1367/A04-130R.1

8. Coles N, Bremer K, Kives S, Zhao X, Hamilton J. Utility of the oral glucose tolerance test to assess glucose abnormalities in adolescents with polycystic ovary syndrome. J Pediatr Adolesc Gynecol. 2016;29(1):48-52. https://doi.org/10.1016/j.jpag.2015.06.004

9. Patel SS, Truong U, King M, Ferland A, Moreau KL, Dorosz $J$, et al. Obese adolescents with polycystic ovarian syndrome have elevated cardiovascular disease risk markers. Vasc Med. 2017;22(2):85-95. https://doi.org/10.1177/1358863X16682107

10. Iwata MC, Porquere L, Sorpreso IC, Baracat EC, Soares Júnior $J M$. Association of oral contraceptive and metformin did not improve insulin resistance in women with polycystic ovary syndrome. Rev Assoc Med Bras (1992). 2015;61(3):215-9. https://doi.org/10.1590/1806-9282.61.03.215

11. Zegher F, Lopez-Bermejo A, Ibáñez L. Adipose tissue expandability and the early origins of PCOS. Trends Endocrinol Metab. 2009;20(9):418-23. https://doi.org/10.1016/j.tem.2009.06.003

12. Zegher F, Beltrán CG, López-Bermejo A, Ibáñez L. Metformin for rapidly maturing girls with central adiposity: less liver fat and slower bone maturation. Horm Res Paediatr. 2018;89(2):13640. https://doi.org/10.1159/000479369

13. Zegher F, López-Bermejo A, Ibáñez L. Central obesity, faster maturation, and 'PCOS' in girls. Trends Endocrinol Metab. 2018;29(12):815-8. https://doi.org/10.1016/j.tem.2018.09.005

14. Ollila MM, Piltonen T, Puukka K, Ruokonen A, Järvelin MR, Tapanainen JS, et al. Weight gain and dyslipidemia in early adulthood associate with polycystic ovary syndrome: prospective cohort study. J Clin Endocrinol Metab. 2016;101(2):739-47. https://doi.org/10.1210/jc.2015-3543

15. He Y, Tian J, Blizzard L, Oddy WH, Dwyer T, Bazzano LA, et al. Associations of childhood adiposity with menstrual irregularity and polycystic ovary syndrome in adulthood: the childhood determinants of adult health study and the bogalusa heart study. Hum Reprod. 2020;35(5):1185-98. https://doi.org/10.1093/humrep/deaa069
16. Özgen IT, Oruçlu Ş, Selek S, Kutlu E, Guzel G, Cesur Y. Omentin-1 level in adolescents with polycystic ovarian syndrome. Pediatr Int. 2019;61(2):147-51. https://doi.org/10.1111/ped.13761

17. Malpique R, Sánchez-Infantes D, Garcia-Beltran C, Taxerås SD, López-Bermejo A, Zegher F, et al. Towards a circulating marker of hepato-visceral fat excess: S100A4 in adolescent girls with polycystic ovary syndrome - evidence from randomized clinical trials. Pediatr Obes. 2019;14(5):e12500. https://doi. org/10.1111/ijpo.12500

18. Khashchenko E, Vysokikh M, Uvarova E, Krechetova L, Vtorushina V, Ivanets T, et al. Activation of systemic inflammation and oxidative stress in adolescent girls with polycystic ovary syndrome in combination with metabolic disorders and excessive body weight. J Clin Med. 2020;9(5):1399. https:// doi.org/10.3390/jcm9051399

19. Rosenfield RL, Ehrmann DA. The pathogenesis of polycystic ovary syndrome (PCOS): the hypothesis of PCOS as functional ovarian hyperandrogenism revisited. Endocr Rev. 2016;37(5):467-520. https://doi.org/10.1210/er.2015-1104

20. McCartney CR, Prendergast KA, Chhabra S, Eagleson CA, Yoo R, Chang RJ, et al. The association of obesity and hyperandrogenemia during the pubertal transition in girls: obesity as a potential factor in the genesis of postpubertal hyperandrogenism. J Clin Endocrinol Metab. 2006;91(5):171422. https://doi.org/10.1210/jc.2005-1852

21. Li L, Feng Q, Ye M, He Y, Yao A, Shi K. Metabolic effect of obesity on polycystic ovary syndrome in adolescents: a metaanalysis. J Obstet Gynaecol. 2017;37(8):1036-47. https://doi. org/10.1080/01443615.2017.1318840

22. Ebersole AM, Bonny AE. Diagnosis and treatment of polycystic ovary syndrome in adolescent females. Clin Obstet Gynecol. 2020;63(3):544-52. https://doi.org/10.1097/ GRF.0000000000000538

23. Koivuaho E, Laru J, Ojaniemi M, Puukka K, Kettunen J, Tapanainen JS, et al. Age at adiposity rebound in childhood is associated with PCOS diagnosis and obesity in adulthoodlongitudinal analysis of BMI data from birth to age 46 in cases of PCOS. Int J Obes (Lond). 2019;43(7):1370-9. https://doi. org/10.1038/s41366-019-0318-z.

24. Peña AS, Witchel SF, Hoeger KM, Oberfield SE, Vogiatzi MG, Misso M, et al. Adolescent polycystic ovary syndrome according to the international evidence-based guideline. BMC Med. 2020;18(1):72. https://doi.org/10.1186/s12916-020-01516-x.

25. Soares-Júnior JM, Sá MFS, Baracat EC. New criteria for the clinical diagnosis of hyperandrogenism in polycystic ovarian syndrome and the risk of overdiagnosis. Rev Bras Ginecol Obstet. 2019;41(6):361-2. https://doi.org/10.1055/s-0039-1693530

26. Dumont A, Robin G, Dewailly D. Anti-Müllerian hormone in the pathophysiology and diagnosis of polycystic ovarian syndrome. Curr Opin Endocrinol Diabetes Obes. 2018;25(6):377-84. https://doi.org/10.1097/MED.0000000000000445

27. Kim JY, Tfayli H, Michaliszyn SF, Lee S, Nasr A, Arslanian S. Anti-Müllerian hormone in obese adolescent girls with polycystic ovary syndrome. J Adolesc Health. 2017;60(3):333-9. https:// doi.org/10.1016/j.jadohealth.2016.10.015

28. Michaliszyn SF, Lee S, Tfayli H, Arslanian S. Polycystic ovary syndrome and nonalcoholic fatty liver in obese adolescents: association with metabolic risk profile. Fertil Steril. 2013;100(6):1745-51. https://doi.org/10.1016/j.fertnstert.2013.08.015 
29. Emeksiz HC, Bideci A, Nalbantoğlu B, Nalbantoğlu A, Çelik C, Yulaf $Y$, et al. Anxiety and depression states of adolescents with polycystic ovary syndrome. Turk J Med Sci. 2018;48(3):531-6. https://doi.org/10.3906/sag-1708-131

30. Milsom SR, Nair SM, Ogilvie CM, Stewart JM, Merry SN. Polycystic ovary syndrome and depression in New Zealand adolescents. J Pediatr Adolesc Gynecol. 2013;26(3):142-7. https://doi.org/10.1016/j.jpag.2012.11.013

31. Vine DF, Wang Y, Jetha MM, Ball GD, Proctor SD. Impaired ApoBLipoprotein and Triglyceride Metabolism in obese adolescents with polycystic ovary syndrome. J Clin Endocrinol Metab. 2017;102(3):970-82. https://doi.org/10.1210/jc.2016-2854

32. Hughan KS, Tfayli $H$, Warren-Ulanch JG, Barinas-Mitchell $E$, Arslanian SA. Early biomarkers of subclinical atherosclerosis in obese adolescent girls with polycystic ovary syndrome. J Pediatr. 2016;168:104-11.e1. https://doi.org/10.1016/j. jpeds.2015.09.082

33. Cree-Green M, Cai N, Thurston JE, Coe GV, Newnes L, GarciaReyes $Y$, et al. Using simple clinical measures to predict insulin resistance or hyperglycemia in girls with polycystic ovarian syndrome. Pediatr Diabetes. 2018;19(8):1370-8. https://doi. org/10.1111/pedi.12778

34. Dokras A, Witchel SF. Are young adult women with polycystic ovary syndrome slipping through the healthcare cracks? J Clin Endocrinol Metab. 2014;99(5):1583-5. https://doi.org/10.1210/ jc. 2013-4190

35. Curi DD, Fonseca AM, Marcondes JA, Almeida JA, Bagnoli VR, Júnior Soares JM, et al. Metformin versus lifestyle changes in treating women with polycystic ovary syndrome. Gynecol Endocrinol. 2012;28(3):182-5. https://doi.org/10.3109/095 13590.2011.583957

36. Legro RS, Arslanian SA, Ehrmann DA, Hoeger KM, Murad MH, Pasquali $R$, et al. Diagnosis and treatment of polycystic ovary syndrome: an Endocrine Society clinical practice guideline. J Clin Endocrinol Metab. 2013;98(12):4565-92. https://doi. org/10.1210/jc.2013-2350

37. Reinehr T, Kulle A, Rothermel J, Knop-Schmenn C, Lass N, Bosse $C$, et al. Longitudinal analyses of the steroid metabolome in obese PCOS girls with weight loss. Endocr Connect. 2017;6(4):213-24. https://doi.org/10.1530/EC-17-0051 .

38. Marzouk TM, Sayed Ahmed WA. Effect of Dietary Weight Loss on Menstrual Regularity in Obese Young Adult Women with Polycystic Ovary Syndrome. J Pediatr Adolesc Gynecol. 2015;28(6):457-61. https://doi.org/10.1016/j.jpag.2015.01.002.

39. Lass $N$, Kleber M, Winkel K, Wunsch R, Reinehr T. Effect of lifestyle intervention on features of polycystic ovarian syndrome, metabolic syndrome, and intima-media thickness in obese adolescent girls. J Clin Endocrinol Metab. 2011;96(11):353340. https://doi.org/10.1210/jc.2011-1609
40. Neves LPP, Marcondes RR, Maffazioli GN, Simões RS, Maciel GAR, Soares Junior JM, et al. Nutritional and dietary aspects in polycystic ovary syndrome: insights into the biology of nutritional interventions. Gynecol Endocrinol. 2020;36(12):1047-50. https://doi.org/10.1080/09513590.2020.1822797.

41. Wong JM, Gallagher M, Gooding H, Feldman HA, Gordon CM, Ludwig DS, Ebbeling CB. A randomized pilot study of dietary treatments for polycystic ovary syndrome in adolescents. Pediatr Obes. 2016;11(3):210-20. https://doi.org/10.1111/ ijpo. 12047

42. Teede HJ, Misso ML, Costello MF, Dokras A, Laven J, Moran L, et al. Recommendations from the international evidence-based guideline for the assessment and management of polycystic ovary syndrome. Hum Reprod. 2018;33(9):1602-18. https:// doi.org/10.1093/humrep/dey256

43. Stoner L, Beets MW, Brazendale K, Moore JB, Weaver RG. Exercise dose and weight loss in adolescents with overweightobesity: a meta-regression. Sports Med. 2019;49(1):83-94. https://doi.org/10.1007/s40279-018-01040-2

44. Simon S, Rahat $H$, Carreau AM, Garcia-Reyes $Y$, Halbower A, Pyle $L$, et al. Poor sleep is related to metabolic syndrome severity in adolescents with PCOS and obesity. J Clin Endocrinol Metab. 2020;105(4):e1827-34. https://doi.org/10.1210/ clinem/dgz285

45. Allen HF, Mazzoni C, Heptulla RA, Murray MA, Miller N, Koenigs $L$, et al. Randomized controlled trial evaluating response to metformin versus standard therapy in the treatment of adolescents with polycystic ovary syndrome. J Pediatr Endocrinol Metab. 2005;18(8):761-8. https://doi.org/10.1515/ jpem.2005.18.8.761

46. Hoeger K, Davidson K, Kochman L, Cherry T, Kopin L, Guzick DS. The impact of metformin, oral contraceptives, and lifestyle modification on polycystic ovary syndrome in obese adolescent women in two randomized, placebo-controlled clinical trials. J Clin Endocrinol Metab. 2008;93(11):4299-306. https://doi. org/10.1210/jc.2008-0461

47. Ibáñez L, Oberfield SE, Witchel S, Auchus RJ, Chang RJ, Codner E, et al. An international consortium update: pathophysiology, diagnosis, and treatment of polycystic ovarian syndrome in adolescence. Horm Res Paediatr. 2017;88(6):371-95. https:// doi.org/10.1159/000479371

48. Dabadghao P. Polycystic ovary syndrome in adolescents. Best Pract Res Clin Endocrinol Metab. 2019;33(3):101272. https:// doi.org/10.1016/j.beem.2019.04.006

49. Ibáñez L, Del Río L, Díaz M, Sebastiani G, Pozo ÓJ, López-Bermejo $A$, et al. Normalizing ovulation rate by preferential reduction of hepato-visceral fat in adolescent girls with polycystic ovary syndrome. J Adolesc Health. 2017;61(4):446-53. https://doi. org/10.1016/j.jadohealth.2017.04.010 